\title{
A Wirelessly Controlled Robot-based Smart Irrigation System by Exploiting Arduino
}

\author{
Ahmed Hassan ${ }^{1}$, Hafiz Muhammad Abdullah ${ }^{2}$, Umar Farooq ${ }^{3}$, Adil Shahzad ${ }^{4}$, Rao Muhammad Asif ${ }^{5}$, Faisal \\ Haider $^{6}$, Ateeq Ur Rehman ${ }^{7}$ \\ 1, 2, 3, 4,5,6 Department of Electrical Engineering, The Superior College, Lahore, Pakistan \\ ${ }^{7}$ College of Internet of Things Engineering, Hohai University, Changzhou 213022, China \\ ${ }^{7}$ Department of Electrical Engineering, Government College University, Lahore 54000, Pakistan
}

Email: 1ahmedhassan101997@gmail.com, 2abdullahsahu221@gmail.com,3superior.umar8671@gmail.com, 4basraadil43@gmail.com, ${ }^{4}$ rao.m.asif@ superior.edu.pk, ${ }^{6}$ faisal.haider@ superior.edu.pk, ${ }^{7}$ ateqrehman@gmail.com

\begin{abstract}
Bringing automation in the farming system is the need of the modern era. The shortcomings of the manual agriculture system can be rectified by exploiting the automatic process which results in higher production of crops. An automated remotely controlled system is proposed that can fulfill the water usage for agricultural land. The proposed smart irrigation system is developed that will irrigate the field around acres at a time. A remotely controlled robot has been developed that will be powered by photo-voltaic panels. The robot has been wirelessly controlled through an application. Different sensors and a high pixel camera are attached with a robot to check the condition of crops and sense the condition of the soil. The field will be divided into different sectors. For commercial purposes, the robot will be gone through all sectors and sense the condition of the soil that will further send the data through the GSM module to the phone. Furthermore, the developed application communicates the collected information to the PC/Laptop.
\end{abstract}

Keywords - Smart Irrigation, Real-Time Automation, Solar, Photovoltaic (PV), Crops, Soil.

\section{INTRODUCTION}

As we already know about the importance of agriculture in our daily lives. Living within this most advanced era, the biological system of people only depends upon the agriculture of their country. By keeping a good biological system, a good human personality could be developed. People get food, vegetables, etc., through their agricultural land. To keep our agricultural land perfect, we need an irrigation system. Irrigation is the process of watering our agricultural field. Irrigation is done through a manual process or automation process. In the manual process, the farmers do irrigation by themselves. This method has a very low initial cost. However, in the automation process, the irrigation is done through remote-controlled devices. This process is most efficient and simplest than manual irrigation process but its initial cost is quite high as compared to the manual process and it is also a time-saving process. In the past, many artificial techniques have been discovered to make the irrigation process easier [1]. Some of them were very efficient but they also had a few major drawbacks such as non-portable devices and can only irrigate a single area of the field at a time.

The soil is the most important medium for plant growth. However, various parameters including soil moisture, $\mathrm{PH}$ of soil, temperature, and humidity varies from region to region. Testing of the soil for nutrients gives valuable information about the soil which can be used to optimize plant growth. The proposed project can be controlled using threshold values of parameters set along with commands through the webpage. The proposed system turns "on" and "off" depending upon the set values and can be controlled by the user. The main benefit of the proposed system is its portability and low maintenance cost because it is powered by the photovoltaic (PV) panels. Furthermore, the proposed model not just irrigates the field but it also has the ability to kill the bacteria.

The automatic irrigation systems are applied in many developed countries to avoid the wastage of water. The scope of the proposed project is important because it irrigates the maximum amount of field and monitors the land remotely. A solar enabled robot is used to capture the condition of crops through a high pixel camera and sensors. If the measured value of soil moisture, humidity, temperature, and the water level is less or above the set threshold, the farmer got notified via the GSM cellular network. Proper action is taken timely to add the soil nutrients through an irrigation pipeline, to spray the field that kills bacteria, and to maintain the desired threshold values [2].

A large amount of freshwater is used in agriculture worldwide. The ratio would be increasing with time due to the rapid growth in population. When the population increase, the demand for food and water will also be increased. As we already know that all the food comes from our agricultural land. Water wastage has been always a major concern for our society in daily life. Water availability varies drastically from region to region. Some regions have plenty of water available and some face scarcity of water. Managing water resources for agriculture is of extreme importance. Water wastage is to be minimized on an urgent basis as the water consumption is increasing with the population growth rate [3]. To overcome these losses a robotics-based irrigation system is developed in which the maximum field will be irrigated. The field is distributed into different areas. The robot goes through all these areas sequentially to sense the condition of the field and communicates the collected information via message along 
with the GSM module through an application of the mobile phone.

The rest of the paper is organized as section II contains the literature review. The methodology is illustrated in Section III. Simulations and results are presented in Section IV along with the conclusion in Section V.

\section{LITERATURE REVIEW}

In [4], the authors have provided a detailed review of the existing solar-powered smart irrigation system. The authors have introduced a technique in which they did irrigation through solar energy. The concept has been demonstrated in Fig. 1. They generated energy from PV panels for the irrigation process. Although, this technique uses renewable energy but it had some drawbacks such as its initial cost were too high and it used a lot of space. In [5], a new technique has been established for monitoring the moisture level of soil based on wireless sensor network. They presented the architecture of their project and implemented decisions through real-time data. It had also some drawbacks such as high maintenance costs and difficult installation.

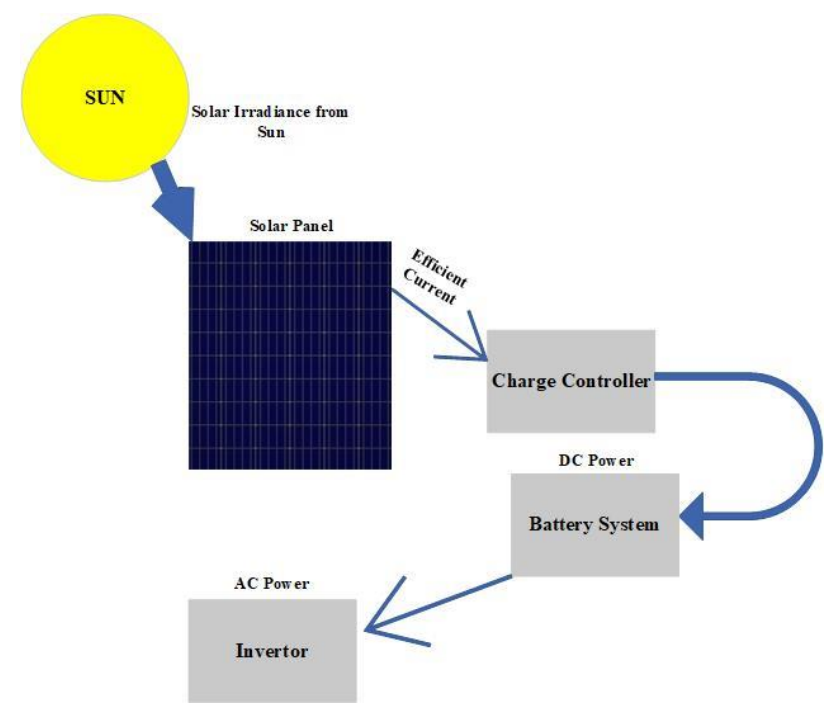

Fig. 1. Solar Energy Generation Process for Smart Irrigation.

Authors in [6, 7], proposed an improved automated irrigation system. They had proposed localized moisture in which there was a connection between a head of sprinkler and water supply through a pipe under some pressure. This method was highly efficient but during the case of heavy wind, the water becomes drifting. Several other works that have presented several designs for the improvement of smart irrigation system but as our work is more inclined towards smart irrigation so we have developed a robot that can be moved into the maximum area of the field for irrigation and it will capture the condition of crops through high pixel camera. In recent years, researchers have tried their best to establish a system that should be renewable and would easily irrigate the maximum amount of area at a time but they have not achieved 100 percent accuracy yet. In $[8,9]$, the authors have developed an algorithm that successfully extracts the distribution of covered temperature. In [10], a GSM-based prototype for the automatic irrigation system has been proposed. Furthermore, in $[11,12]$, authors have established a technique of duplex communication. The main benefit of this technique is that it gave an overview of data and timetable of the irrigation process, using an algorithm of a cellular internet interface. In [13 14], the authors have provided an idea of low cost based wirelessly controlled irrigation system. The main purpose of this technique was to save the maximum amount of water that always waste during the watering of the agricultural field. The main drawback of this technique was its maintenance cost. The authors in [1518], have designed a fuzzy logic-based smart irrigation technique. In our current work, the following equation (1) is used for the detection and reduction of error:

$$
\text { m.s.e }=\frac{1}{Z} \cdot \sum_{n=1}^{Z}\left(u_{n}-\hat{u}_{n}\right)^{2}
$$

where;

- $\mathrm{Z} \quad=$ trained sample numbers

- m.s.e = mean square error

- $u_{n} \& \hat{u}_{n}=$ outputs

The researchers in [19-21], had discovered a new technique in the agricultural market named as a center pivot irrigation system. By dividing their system into two separate parts they controlled their system through a micro-controller. All the components were connected and rotating along with a central point while on the other hand the watering process was done through sprinklers to crops.

A low initial cost, the programmable logic controller (PLC) based irrigation system was developed by the authors in $[22,23]$ to improve the economic level of the market. The system was reliable with easy implementation. The main working of their system was to control the PH level and humidity level of the soil and further sent the data to the logic controller that was used as a switch. The main drawback of this system was that the protection of the sensors kit was not efficient. The authors in [24-28] have provided a system that works on the principle of the Internet of Things (IoT). The main benefit of this was that more than one task would be performed at a time through cloud computing. This system had almost finished the appearance of workers/farmers for task formation. In [29, 30], the smart underground irrigation system has been provided by the authors. It was a noiseless based irrigation system having the best economic level in the agricultural market. The system was beneficial because it could automatically water the plants/crops in the absence of farmers. Due to the quite complicated installation, this system failed in the market very badly. The authors of [31], have designed an artificial intelligence (AI) based irrigation system. This system was based on self-made decisions by the machine and it was also a self-healing device. Like previous irrigation systems as we discussed earlier this system had also some major drawbacks such as high initial cost, high running cost, and due to the required programming language this system was not understandable for ordinary workers. Also, the concept of blockchain has been used in [32] to monitor the agricultural land remotely.

\section{METHODOLOGY}

The main methodology steps that are used to make out project successful are given as follows: 


\section{A. Schematic Diagram}

The schematic/structured diagram demonstrates the working of the project and shows the tasks performed by different components to irrigate the maximum amount of field as much as we can. The first major process in the circuit is to develop a wireless controlled robot, in which we integrate the Bluetooth module with Arduino which is further connected to an application. A command to the robot motors is sent through mobile by using an android application. The robot contains a camera for checking the condition of crops and also has a kit of sensors i.e. sensor of humidity, the sensor for measuring moisture level in soil, the sensor for measuring ph level of water, the optical transducer to measure the number of nutrients i.e. Nitrogen, Phosphorus and Potassium (NPK) in the soil. The field will be distributed into different areas. The robot will be going through all these areas sequentially.

For the commercial level, two pipelines will be set in every two areas by attaching these pipelines with the robot in the form of tanks. One pipe line is for irrigation and other is for the spray to kill the pesticides in the field. The nutrients container will be attached to the irrigation pipeline when our system will show the deficiency of nutrients in the soil we will give the command by using the GSM module and the nutrients will be mixed in the soil through the robot. The structured diagram of our project is shown in Fig. 2.

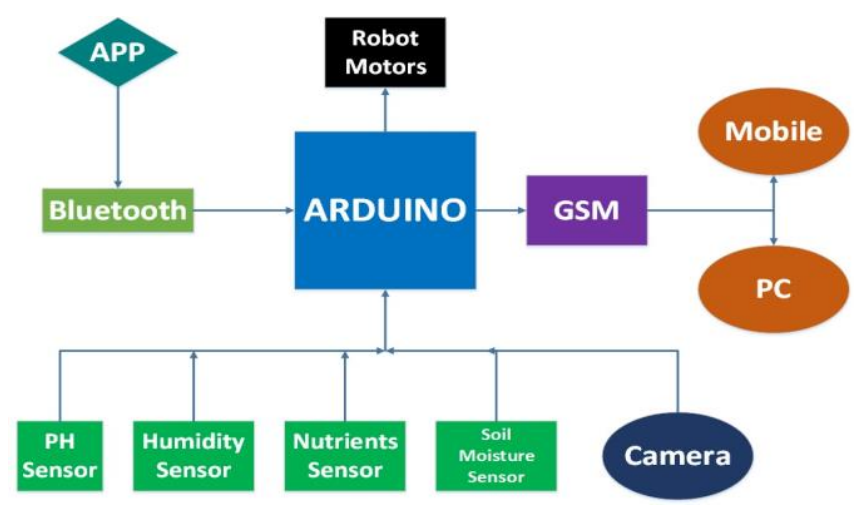

Fig. 2. Structured Diagram for Smart Irrigation Process

\section{B. Proposed Model}

The mechanical model of our project is shown in Fig. 3. In, this mechanical model different components are attached for specific functions. Point no. 1 indicates that the robot is running through solar energy with the help of two photovoltaic plates. While point no. 2 shows robot tyres and these tyres of the robot are controlled by mobile App. The point no. 3 is for pesticide spray that is used for killing the bacteria present in the agricultural field. A high pixel wireless camera is attached at point no. 4 which is used for monitoring the condition of crops/field. There is a kit of sensors for performing different specific functions attached at point no.5. Furthermore, a Bluetooth module is attached at point no. 6 for managing a linkage between mobile application App and robot. Point no.7 is used for a tank in which two tanks are placed one is for watering and the other one is for pesticide spray.

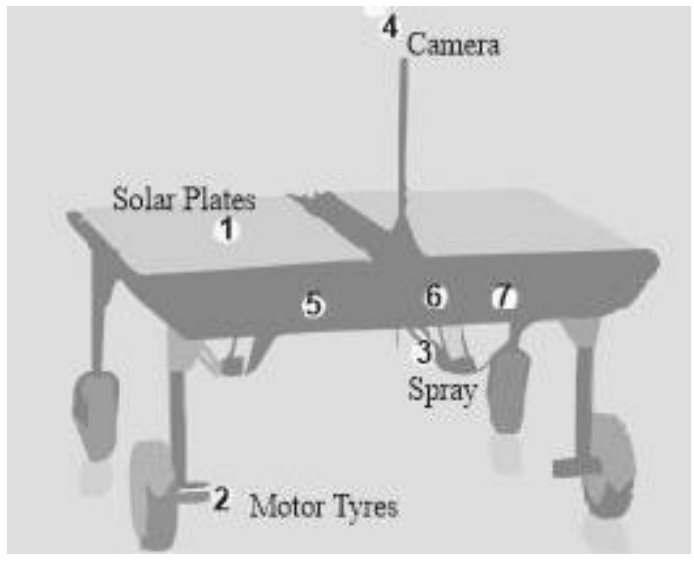

Fig. 3. Proposed Mechanical Robotic Model

\section{Main Components List}

The main components used for the hardware implementation of the robot-based smart irrigation system are Arduino Mega 2560, HC-05 module, optocoupler 6N139, HBridge L298, relay module, tyres, servo motors, solar plates, and battery, etc. The detail of some of these components will be discussed in the coming sections.

\section{Arduino Mega 2560}

A microcontroller device Arduino Mega 2560 is used for controlling the embedded components connected to it for specific functions [33]. The measured analog voltages were derived by using a simple equation (2):

$$
\text { A.M.V }=\frac{\text { ADC's Reading }}{\text { ADC's Resolutiom }} *(\text { System Voltages })
$$

There are the following reasons for using Arduino mega 2560 given in Table I.

TABLE I. FEATURES OF ARDUINO MEGA

\begin{tabular}{|c|c|}
\hline Specifications & Atmega 2560 \\
\hline Dimension & $4 \times 2.1$ in \\
\hline Clock Speed & $16 \mathrm{MHz}$ \\
\hline Digital I/O Pins & 15 \\
\hline Shield Compatibility & Yes \\
\hline Flash Memory & 256 \\
\hline
\end{tabular}

\section{E. H-Bridge}

An H-bridge is also known as an L298 motor driver. This motor driver is used in our project for controlling the tyres of the robot. There are also other motor drivers in the market such as L293 but have the drawback of low input voltage power. We prefer L298 motor driver due to its high input voltage power. The specifications of this bridge are given in Table II.

The power consumption of H-bridge is quite low i.e., $36 \mathrm{~mA}$ with supply voltages of $5 \mathrm{~V}$. It has independent direction, speed, and braking system for each motor. Due to this motor driver, our robot can move in both clockwise and anticlockwise directions. By pressing the appropriate button from the developed mobile application, the motors of robot start moving in the forward direction and vice versa [34]. 
TABLE II. FEATURES OF H-BRIDGE

\begin{tabular}{|c|c|c|c|c|c|c|c|c|}
\hline \multirow[t]{3}{*}{$\begin{array}{l}\text { Sr. } \\
\#\end{array}$} & \multirow{3}{*}{$\begin{array}{l}\text { Duty } \\
\text { Cycl } \\
\text { e } \\
(\%)\end{array}$} & \multirow{3}{*}{$\begin{array}{l}\text { Noise } \\
\text { Freq } \\
\text { (MHz } \\
\text { ) }\end{array}$} & \multirow{2}{*}{\multicolumn{3}{|c|}{$\begin{array}{l}\begin{array}{l}\text { Radiated } \\
(\text { dB.A/m) }\end{array} \\
\text { Heat Sink }\end{array}$}} & \multicolumn{3}{|c|}{$\begin{array}{ll}\begin{array}{l}\text { Dradiated } \\
(\text { dB.A } / \mathbf{m})\end{array} & \text { EMI } \\
\end{array}$} \\
\hline & & & & & & & Ieat Si & \\
\hline & & & $\begin{array}{l}\text { Floa } \\
\mathrm{t}\end{array}$ & $\begin{array}{l}\text { Groun } \\
\text { d }\end{array}$ & $\begin{array}{l}\mathrm{Ic} \\
\mathrm{m}\end{array}$ & $\begin{array}{l}\text { Floa } \\
\mathrm{t}\end{array}$ & $\begin{array}{l}\text { Groun } \\
\text { d }\end{array}$ & $\begin{array}{l}\text { Lo } \\
w\end{array}$ \\
\hline \multirow{9}{*}{$\begin{array}{l}\mathrm{HB} \\
\mathrm{C}\end{array}$} & \multirow[t]{3}{*}{75} & 30 & 8 & 5 & 6 & -17 & -19 & -18 \\
\hline & & 55 & 7 & 7 & 8 & -15 & -15 & -14 \\
\hline & & 130 & 6 & 4 & 6 & -12 & $\begin{array}{l}-14 \\
\end{array}$ & $\begin{array}{l}-12 \\
\end{array}$ \\
\hline & \multirow[t]{3}{*}{50} & 30 & 5 & 5 & 5 & -6 & -6 & -6 \\
\hline & & 55 & 7 & 7 & 7 & -7 & -7 & -7 \\
\hline & & 130 & 5 & 5 & 5 & -4 & -4 & -4 \\
\hline & \multirow[t]{3}{*}{25} & 30 & 4 & 4 & 4 & -9 & -9 & -9 \\
\hline & & 55 & 6 & 6 & 6 & -8 & -8 & -8 \\
\hline & & 130 & 4 & 4 & 4 & -8.5 & -8.5 & -8 \\
\hline
\end{tabular}

The table II shows the measurements of radiated and Dradiated electromagnetic influence (EMI) of the half-bridge circuit (HBC) in different duty cycles. It is observed in radiated EMI that a greater duty cycle of $\mathrm{H}$-bridge causes low noise current $\left(\mathrm{I}_{\mathrm{cm}}\right)$ with high noise frequency. On the other hand, in the Dradiated EMI case greater duty cycle of $\mathrm{H}$ bridge causes high noise current $\left(\mathrm{I}_{\mathrm{cm}}\right)$ with high noise frequency [35].

\section{F. Controlling Through App}

A mobile app was developed to control the robot as shown in Fig. 4. Robot acted according to the specific commands that were given in the Application with the help of high-level programming language.

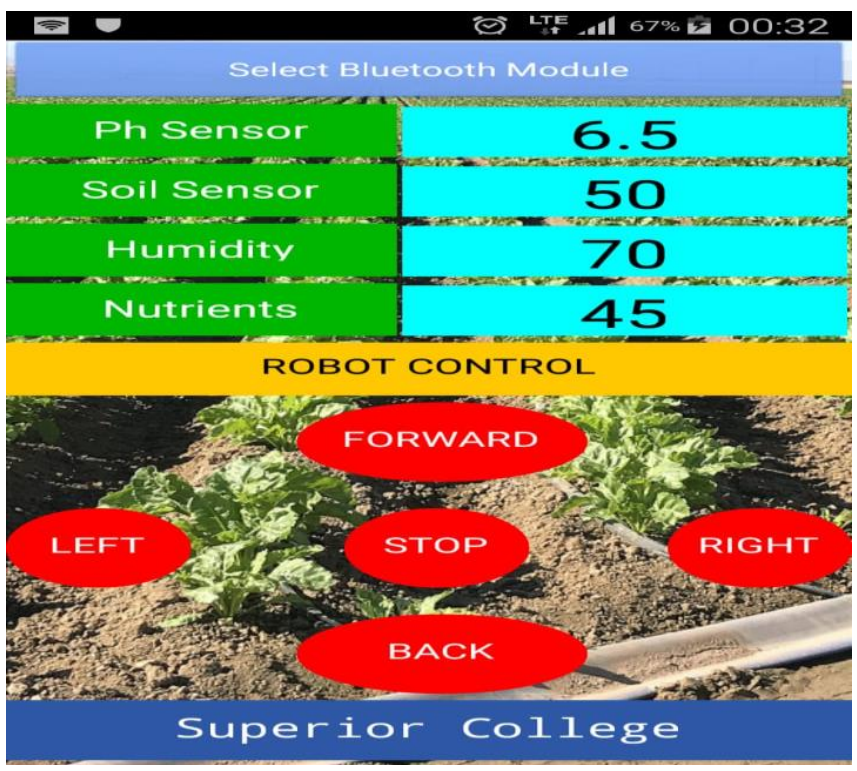

Fig. 4. Mobile Application

A threshold value is fixed to each sensor in coding. When a sensor cut off that threshold value in form of voltages, we were notified through a microcontroller to a mobile app.

TABLE III. THRESHOLD PARAMETER

\begin{tabular}{|c|c|}
\hline Sensor & Threshold Value \\
\hline PH & $14 \mathrm{~V}$ \\
\hline Soil & $50 \mathrm{~V}$ \\
\hline Nutrients & $50 \mathrm{~V}$ \\
\hline Humidity & $50 \mathrm{~V}$ \\
\hline
\end{tabular}

\section{SIMULATION AND RESULTS}

In this part of the paper, two flow charts have been designed for a better understanding of the whole proposed smart irrigation process. In Fig. 5, the mechanism to control the supply of water through different valves is demonstrated. While in Fig. 6, the flowchart illustrates how pesticide spray kills the bacteria present in the crops/field.

Furthermore, the schematic diagram of our project is designed by using Proteus as shown in Figures 7-10. Also, a hex file of the designed project is created for uploading that project using $\mathrm{C}++$ code in the Arduino platform.

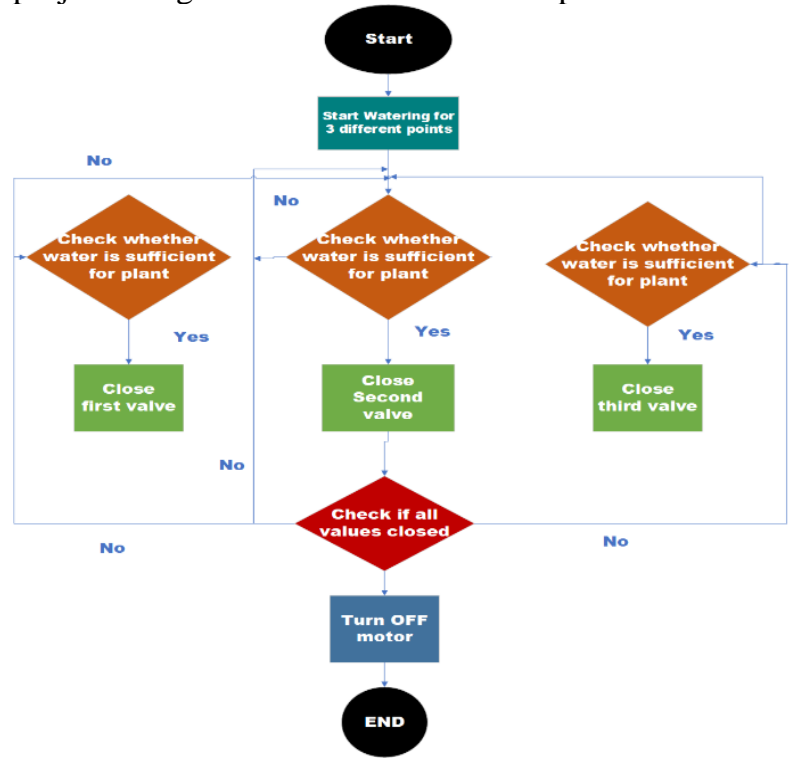

Fig. 5. Flowchart to Control the Watering for Plants.

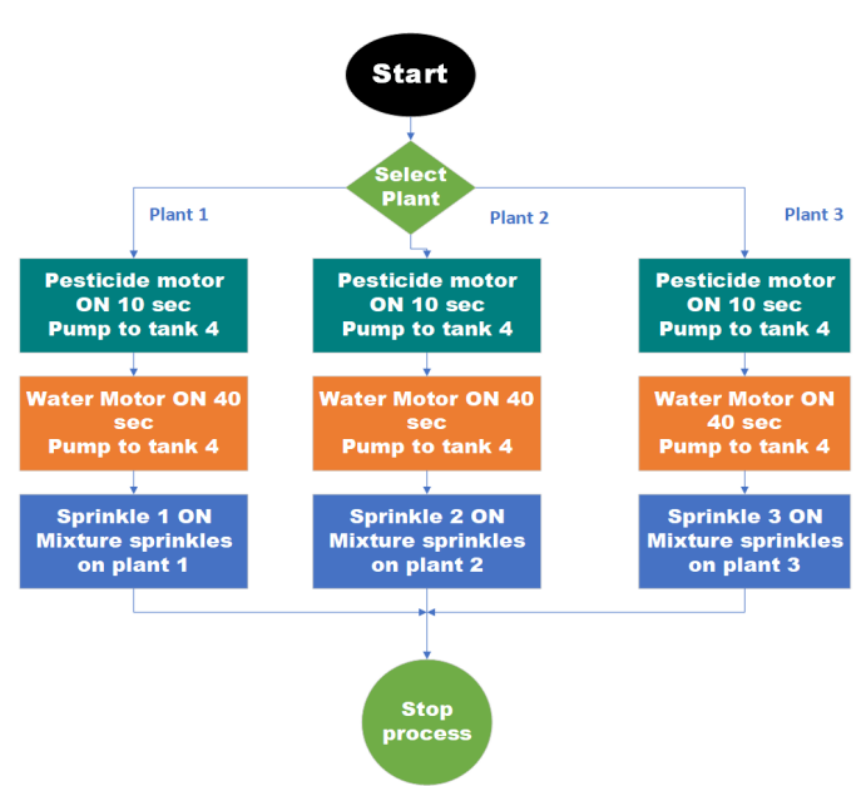

Fig. 6. Flowchart of the Spray Process.

A. Case 1

The first case is for the $\mathrm{Ph}$ sensor, as we have already defined the threshold value for the $\mathrm{Ph}$ level for the soil in our Arduino code. So, when soil overshoots that predefined value our robotics system will detect it, and LED start blinking. The schematic design for the Ph sensor is shown in Fig. 7. 


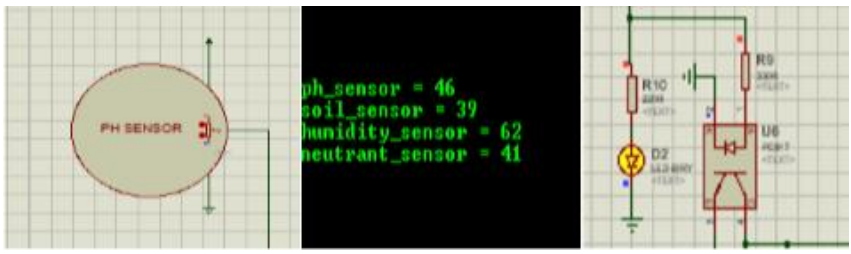

Fig. 7. Schematic Diagram of PH Sensor

\section{B. Case 2}

The second case is for soil sensor, this sensor will detect the moisture present in the soil of the field. According to this moisture's level, our system will decide either to irrigate or not. As we have already defined the threshold value for moisture level for the soil in our Arduino code. So, when the moisture level of soil overshoots that predefined value our robotics system will detect it, and LED starts blinking. As shown in Fig. 8.

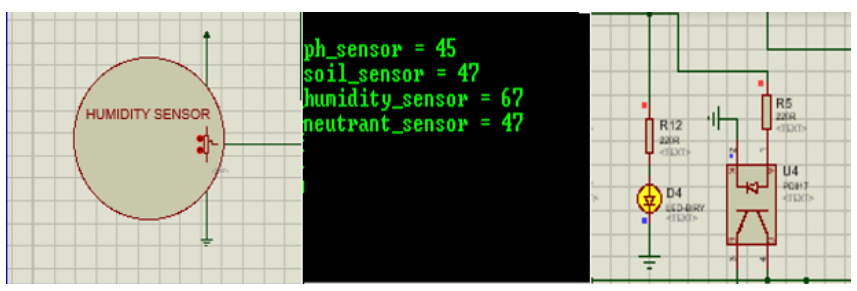

Fig. 8. Schematic Diagram of Humidity Sensor

\section{Case 3}

This case is for nutrients sensor as shown in Fig. 9. It means this sensor will determine the number of nutrients in soil such that nitrogen, potassium, and phosphorus and according to this level our system will decide either to irrigate or not. As we have already defined the threshold value for nutrients present in the soil in our Arduino code. So, in case of nutrients i.e., NPK below than the average value of the threshold level, our LED connected to that sensor will start blinking.

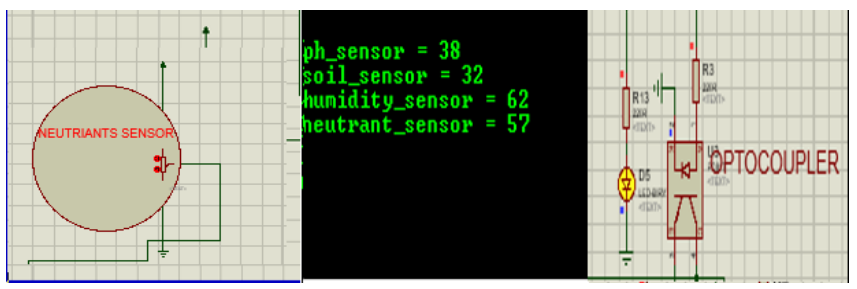

Fig. 9. Schematic Diagram of Nutrients Sensor

\section{Normal Case}

The normal case means when there will be no need to do any task through a robot. In this case threshold values will remain constant and LED will not blink as shown in Fig. 10. Usually, it is a very rare case in normal days. But when this case happens, other tasks could be performed such as killing the bacteria present in the field/crops through pesticide spray or checking the condition of crops through a security camera.

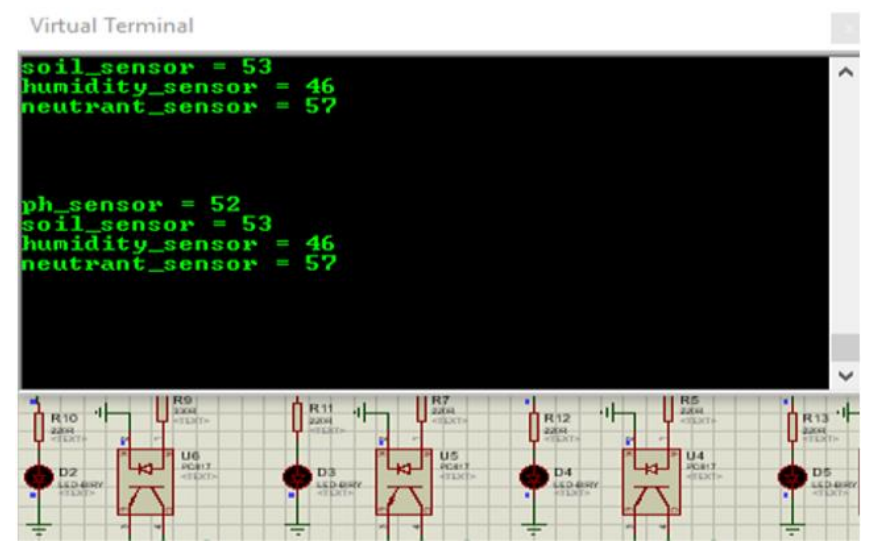

Fig. 10. Normal Case

A threshold value is fixed to each sensor in coding. When a sensor cut off that threshold value, we were notified through GSM to a mobile app.

\section{CONCLUSION}

By using the proposed automated irrigation system, excess wastage of water can be saved that is lost during manual methods. It also improvises the irrigation cycle and renders it a successful one. Furthermore, with this method, water delivery to fields is achieved more efficiently.

The designed automated controlled robot is controlled wirelessly through different commands and the collected information of the field is displayed remotely on the mobile application as well as on the PC of the farmers. Also, the electricity issue is resolved as the robot is solar-powered. Thus, this method has an upper hand over all other methods of irrigation because of its consistency and usability. The maintenance cost of our project is low and in the future, it could be deployed on a commercial basis because of costeffectiveness.

\section{ACKNOWLEDGMENT}

Ahmed Hassan and Ateeq Ur Rehman are co-first authors.

\section{REFERENCES}

[1] Hernandez, Norma Alicia Gonzalez, Mario Erik Torres Gutierrez, Juan Antonio Chavez Murga, and Hussein Maloof Flores. "Remote controlled electrically independent irrigation system." U.S. Patent Application 14/995,287, filed June 22, 2017.

[2] Haule, Joseph, and Kisangiri Michael. "Deployment of wireless sensor networks (WSN) in automated irrigation management and scheduling systems: a review." In Proceedings of the 2nd Pan African International Conference on Science, Computing and Telecommunications (PACT 2014), pp. 86-91, Arusha, 2014.

[3] Rai, Mahendra, Dnyaneshwar Rathod, Gauravi Agarkar, Mudasir Dar, Marian Brestic, Glaucia Maria Pastore, and Mario Roberto Marostica Junior. "Fungal growth promotor endophytes: a pragmatic approach towards sustainable food and agriculture." Symbiosis 62, no. 2, pp. 63$79,2014$.

[4] Ariffin, M. Ruzaimi, S. Shafie, W. Z. W. Hassan, N. Azis, and M. Effendy Ya'acob. "Conceptual design of hybrid photovoltaicthermoelectric generator (PV/TEG) for Automated Greenhouse system." In 2017 IEEE 15th Student Conference on Research and Development (SCOReD), pp. 309-314. IEEE, 2017.

[5] Vellidis, George, Michael Tucker, Calvin Perry, Craig Kvien, and C. Bednarz. "A real-time wireless smart sensor array for scheduling irrigation." Computers and electronics in agriculture 61, no. 1 (2008): 44-50. 
[6] Qiuming, Kuang, Zhao Yandong, and Bai Chenxiang. "Automatic monitor and control system of water saving irrigation." Transactions of the Chinese Society of Agricultural Engineering 2007, no. 6 (2007).

[7] Wójtowicz, Marek, Andrzej Wójtowicz, and Jan Piekarczyk. "Application of remote sensing methods in agriculture." Communications in Biometry and Crop Science 11, no. 1 (2016): 31-50.

[8] Agaian, Sos, and Mehdi Roopaei. "Method and systems for thermal image/video measurements and processing." U.S. Patent Application 14/533,061, filed August 27, 2015.

[9] European Commission, "Report on the Public Consultation on IoT Governance," 2015. http://ec.europa.eu/information_society/newsroom/cf/dae/document. cfm?doc id=1746.

[10] A. U. Rehman, R. M. Asif, R. Tariq and A. Javed, "Gsm based solar automatic irrigation system using moisture, temperature and humidity sensors," 2017 International Conference on Engineering Technology and Technopreneurship (ICE2T), Kuala Lumpur, 2017, pp. 1-4.

[11] Yang, Yanjiang, Haibin Cai, Zhuo Wei, Haibing Lu, and Kim-Kwang Raymond Choo. "Towards lightweight anonymous entity authentication for IoT applications." In Australasian conference on information security and privacy, pp. 265-280. Springer, Cham, 2016

[12] Yang, Yanjiang, Jiqiang Lu, Kim-Kwang Raymond Choo, and Joseph K. Liu. "On lightweight security enforcement in cyber-physical systems." In Lightweight Cryptography for Security and Privacy, pp. 97-112. Springer, Cham, 2015.

[13] Nandurkar, S. R., V. R. Thool, and R. C. Thool. "Design and development of precision agriculture system using wireless sensor network." In 2014 First International Conference on Automation, Control, Energy and Systems (ACES), pp. 1-6. IEEE, 2014.

[14] Gutiérrez, Joaquín, Juan Francisco Villa-Medina, Alejandra NietoGaribay, and Miguel Ángel Porta-Gándara. "Automated irrigation system using a wireless sensor network and GPRS module." IEEE transactions on instrumentation and measurement 63, no. 1 (2013): 166-176.

[15] Kumari, G. Meena, and Dr V. Devi. "Real Time Automation and Monitoring System for Modernized Agriculture." International Journal of Review \& Research in Applied Sciences and Engineering vol3 (2013).

[16] Kim, Yunseop, Robert G. Evans, and William M. Iversen. "Remote sensing and control of an irrigation system using a distributed wireless sensor network." IEEE transactions on instrumentation and measurement 57, no. 7 (2008): 1379-1387.

[17] Wang, Qiang, Andreas Terzis, and Alex Szalay. "A novel soil measuring wireless sensor network." In 2010 IEEE Instrumentation \& Measurement Technology Conference Proceedings, pp. 412-415. IEEE, 2010.

[18] Yoo, Seong-eun, Jae-eon Kim, Taehong Kim, Sungjin Ahn, Jongwoo Sung, and Daeyoung Kim. "A 2 S: automated agriculture system based on WSN." In 2007 IEEE International Symposium on Consumer Electronics, pp. 1-5. IEEE, 2007.

[19] Arampatzis, Th, John Lygeros, and Stamatis Manesis. "A survey of applications of wireless sensors and wireless sensor networks." In Proceedings of the 2005 IEEE International Symposium on, Mediterrean Conference on Control and Automation Intelligent Control, 2005., pp. 719-724. IEEE, 2005.

[20] Suma, N., Samson, S.R., Saranya, S., Shanmugapriya, G. and Subhashri, R., 2017. IOT based smart agriculture monitoring system. International Journal on Recent and Innovation Trends in computing and communication, 5(2), pp.177-181.

[21] Rukhmode, Sandip, Gayatri Vyavhare, Sharda Banot, Abhilash Narad, and R. M. Tugnayat. "IOT based agriculture monitoring system using wemos." In International Conference On Emanations in Modern Engineering Science and Management, pp. 14-19. 2017.

[22] Liu, Hui, Zhijun Meng, and Shuanghu Cui. "A wireless sensor network prototype for environmental monitoring in greenhouses." In 2007 International Conference on Wireless Communications, Networking and Mobile Computing, pp. 2344-2347. IEEE, 2007.

[23] Mekala, Mahammad Shareef, and P. Viswanathan. "A Survey: Smart agriculture IoT with cloud computing." In 2017 international conference on microelectronic devices, circuits and systems (ICMDCS), pp. 1-7. IEEE, 2017.

[24] Sartori, Davide, and Davide Brunelli. "A smart sensor for precision agriculture powered by microbial fuel cells." In 2016 IEEE Sensors Applications Symposium (SAS), pp. 1-6. IEEE, 2016.

[25] Gayatri, M. K., J. Jayasakthi, and GS Anandha Mala. "Providing Smart Agricultural solutions to farmers for better yielding using IoT." In 2015 IEEE Technological Innovation in ICT for Agriculture and Rural Development (TIAR), pp. 40-43. IEEE, 2015.

[26] Abdullah, Aalaa, Shahad Al Enazi, and Issam Damaj. "AgriSys: A smart and ubiquitous controlled-environment agriculture system." In 2016 3rd MEC International Conference on Big Data and Smart City (ICBDSC), pp. 1-6. IEEE, 2016.

[27] Channe, Hemlata, Sukhesh Kothari, and Dipali Kadam. "Multidisciplinary model for smart agriculture using internet-ofthings (IoT), sensors, cloud-computing, mobile-computing \& big-data analysis." Int. J. Computer Technology \& Applications 6, no. 3 (2015): 374-382.

[28] Roopaei, Mehdi, Paul Rad, and Kim-Kwang Raymond Choo. "Cloud of things in smart agriculture: Intelligent irrigation monitoring by thermal imaging." IEEE Cloud computing 4, no. 1 (2017): 10-15.

[29] Mekala, Mahammad Shareef, and P. Viswanathan. "A Survey: Smart agriculture IoT with cloud computing." In 2017 international conference on microelectronic devices, circuits and systems (ICMDCS), pp. 1-7. IEEE, 2017.

[30] Bandara, A. G. N., B. M. A. N. Balasooriya, H. G. I. W. Bandara, K. S. Buddhasiri, M. A. V. J. Muthugala, A. G. B. P. Jayasekara, and D. P. Chandima. "Smart irrigation controlling system for green roofs based on predicted evapotranspiration." In 2016 Electrical Engineering Conference (EECon), pp. 31-36. IEEE, 2016.

[31] Odat, Enas, Jeff S. Shamma, and Christian Claudel. "Vehicle classification and speed estimation using combined passive infrared/ultrasonic sensors." IEEE transactions on intelligent transportation systems 19, no. 5 (2017): 1593-1606.

[32] J. Arshad et al., "A Novel Remote User Authentication Scheme by using Private Blockchain-Based Secure Access Control for Agriculture Monitoring," 2020 International Conference on Engineering and Emerging Technologies (ICEET), Lahore, Pakistan, 2020, pp. 1-9.

[33] A. M. Furqan Durrani, A. U. Rehman, A. Farooq, J. A. Meo and M. T. Sadiq, "An Automated Waste Control Management System (AWCMS) by Using Arduino," 2019 International Conference on Engineering and Emerging Technologies (ICEET), Lahore, Pakistan, 2019, pp. 1-6, doi: 10.1109/CEET1.2019.8711844.

[34] V. Gupta, "Working and analysis of the $\mathrm{H}$ - bridge motor driver circuit designed for wheeled mobile robots," 2010 2nd International Conference on Advanced Computer Control, Shenyang, 2010, pp. 441-444, doi: 10.1109/ICACC.2010.5486818.

[35] Srisawang, A., S. Panaudomsup, and Y. Prempraneerach. "Comparison of EMI Performance of Full-Bridge and Half-Bridge Power Converter." In International Symposium on Nonlinear Theory and its Applications (NOLTA), Xi'an, PRC, pp. 203-306. 2002. 